\title{
FORMAL
}

CREATURES:

GILLES CHÂTELET'S

METAPHORS

BEN WOODARD

BEN WOODARD is a postdoctoral researcher at the Institute for Philosophy and Art Theory (IPK) at Leuphana University in Lüneburg, Germany. His research focuses on the relationship between naturalism and idealism, especially during the long Igth Century. He has published two monographs Slime Dynamics: Generation, Mutation, and the Creep of Life (Zero, 2012) and On an Ungrounded Earth: Towards a New Geophilosophy (Punctum, 2013). His book Schelling's Naturalism: Motion, Space and the Volition of Thought was published in 2019 by Edinburgh University Press. He has also published numerous articles on weird and science fiction. $\mathrm{He}$ is a co-founder of P.S., a philosophy collective at the Performing Arts Forum in St. Erme, France. 
My aim is to explicate Gilles Châtelet's use of metaphor as a philosophical tool. Rather than analysing the philosophical use of metaphor broadly (which in itself would require volumes), I wish to specifically examine how Châtelet sees metaphor as a type of formal creature that is related to both the gesture and the diagram. While Châtelet expresses the movement of the gesture, to the diagram, to the sign, as a rigidification of formal expression of the conceptual act, the function or role of the metaphor is one of uncertain accompaniment in such a process. This is not to reduce metaphor to its usual life as mere rhetorical firework, but instead to understand metaphor as a necessary parasite of the conceptual through its formal phase-changes. In other words, the metaphor is caught between a conceptual place-holder and a vehicle for speculation in which an uncertain concept or practice is injected into already existing ideas, fields, and sciences, in order to take advantage of the surrounding landscape without becoming lost within it. As a secondary goal, outlining Châtelet's understanding of metaphor will serve to instructively complicate his association with Gilles Deleuze.

\section{BREAKING THE GREY}

It's a question of seeking confrontation and of crying Down with grey! Down with the Neutral! Long live Anger! Long Live the Red! We should never forget that grey neutralizes intensities by mixing together all the colours that are already given. Style is not a polite way of thinking: no style, no thinking! Style is a discipline of breaking language out of itself, a martial art of metaphor. The haranguing tone of the pamphlet is a working on language, and style is an entirely integral part of thought qua thought experiment. The effectiveness of the philosophical concept is fuelled by a work of torsion of material language on itself. It's a matter of capturing and organizing the forces that could break through and tear apart 'straight-talking' and 'promoting quality culture.' Note also that, in order to break through, one must understand the Hegelian-Marxist helix not as a routine movement within History, but as a corkscrew that leverages a torsion of natural language. ${ }^{\mathrm{I}}$

In A Martial Art of Metaphor Châtelet is nearly immolated by his own rhetorical excesses as he launches invectives against the neo-liberalization of philosophical thought. Working in the mode of his barbed text

I Gilles Châtelet, A Martial Art of Metaphor: Two Interviews with Gilles Châtelet, trans. R. Mackay, M. Hare and S. Huitre (Windsor Quarry: Urbanomic, 2017), Available Online at https://www.urbanomic.com/document/gilles-chatelet-mental-ecology/ 
To Live and Think Like Pigs, Châtelet nevertheless maintains a strong connection to his earlier work regarding the relation of style to thought. ${ }^{2}$ Even in this political moment we see the connection between thought experiment and style, which is captured in the scientific conceptual use of metaphor. This is further advanced in the example of torsion, and of the corkscrew, which Châtelet argues comes about through the understanding of the relation between mechanics, electricity, and diagrammatic thinking flowing from Schelling, to Faraday, to Hamilton, to Maxwell. We will discuss this below. For now, what is important is to try and understand the immanent to evental shift that occurs in the most abstracted region of expression, that of space itself.

Any detailed inspection of a landscape or of a domain of knowledge presupposes a survey, and the horizon is what endows caution with some style. If this survey were reduced merely to prescribing a horizontal' reading and a 'vertical' reading; it would lead only to a fixed stratification. The survey induces an axis of distribution of the mobilities that reactivate knowledge: The strata become a field, whose exploration implies a norm of virtual grasp of the statements. This norm never offers itself up placidly for analysis and always evades anyone who would seek it 'on the near or far side' of the horizon that controls it. Its withdrawal is always painful and is paid for by a 'metaphorical' dislocation of the field or by its reduction to significant networks subordinated to a code. The implicit pressure of the horizon is like the scar of a gesture ... ${ }^{3}$

Metaphors are thus not a free play of meaning despite their dramatic presentation in To Live and Think Like Pigs. Metaphors are transports whose trespasses across the fields of meaning leave marks (scars) every time the field is realigned, or a space is navigated. There is no easy or carefree investigation-even the horizon which would seem given to us issues a pressure, a weight. It is important to keep in mind that Châtelet does not wish to keep metaphor in purely linguistic dress. Metaphors capture, but imperfectly and violently, the trajectories of the ideas and concepts mucking about. Thus, Châtelet's metaphor about metaphor being a form of martial art must not be read in a generally Heideggerian manner - that language is the prison house of being, that only language can break language. Châtelet's attitude towards Heidegger's philosophical trajectory makes clear the lack of any potential affinity.

Châtelet writes in Autour du vrai-faux rapport d'Éric Alliez: De l'impossibilitédela phénoménologie that Heideggerians embrace akind of para-phenomenology, and that the followers of such pseudo-theological

2 Gilles Châtelet, To Live and Think Like Pigs. The Incitement of Envy and Boredom in Market Democracies, trans. R. Mackay (Windsor Quarry: Urbanomic x Sequence Press, 2014).

3 Gilles Châtelet, Figuring Space: Philosophy, Mathematics, and Physics (London: Springer, 1999), 54 . 
radicality are all aboard a ghost train, "screaming in concert" that no one can understand "the spoils of the Great Heideggerian quivering" before "the angel of the event." Furthermore, these para- or negativelytheological passengers "have a sort of obsession with legerdemain: constructing an $\mathrm{X}$, which would have all the determinations of $\mathrm{X}$ but which is not $\mathrm{X}$ as such. They believe they can get drunk on the nectar dispensed by Chance and Event while they only desperately mimic the pursuit of the absolute epoche."

It should be clear that Châtelet is not telling us that language gives us the lock-pick to being, only that the relation of expression (which is also importantly mathematical, gestural, and diagrammatic) to thought is one that often produces an overhang, an excess which allows thought to test itself against itself. Again, not in terms of finding the meaningfulness of being, but of the proper way to symbolize the actions of thought that cut effectively into the chaos of the world (and not reveal any proper way of being in the world). These cuts, as expressions of thought, can be solidified - while they begin as intuitions they quickly bloom into gestures, then curl up into diagrams, before eventually becoming signs. But these expressions are meant to mangle and rewrite the understanding of the human, to bend space and redraw the interiority of the notion of self. ${ }^{5}$

The very un-Heideggerian quality of such a claim should not be too hard to follow: The matheme, the diagram, the topological tracing of abstract space, is effectively a technique of the self that has just as much, or more power, as discovering the limits of the human as any hermeneutics tangled up with Dasein. ${ }^{6}$

\section{KNOTS OF THE HORIZON, TURNS OF THE SCREW}

Knot theory thus evokes gestures which are classical for it, but completely new in the domain where it is imported as 'notation'. Thus certain a priori not very suggestive complicated formulae of tensor calculus can be condensed in a fulgurating way and launch new calculations. This upsets the very notion of indexation which becomes bi-dimensional in the freeing itself from the successive: It is very much a victory of the

4 Gilles Châtelet, 'Autour du vrai-faux rapport d'Éric Alliez: “De l'impossibilité de la phénoménologie”', in Multitudes, accessible at: http://www.multitudes.net/autour-duvrai-faux-rapport-d-eric/

5 Châtelet discusses this via Foucault and the notion of convexity as a technology of the self in 'Autour du vrai-faux rapport d'Eric Alliez'

6 Here Châtelet unexpectedly functions as a makeshift bridge between Frege and the post-Kantian tradition's interest in mathematics, whether it be Schelling's algebraic topology, Maimon's calculus of magnitudes, or Hegel's pre-paraconsistent logic. Frege's artificial or technical languages suggest a breaking with common language in order to explain the productivity of concepts that are neither strictly found nor made from scratch. For more on this, see Hare and Woodard, 'Anti-Eureka', in Glass Bead 2, Logic Gates, 2017, accessible at: http://www.glass-bead.org/article/anti-eureka/ 
hand that comments on itself, the indexation no longer being delivered by an external 'set', but by a process of deformation and modification of diagrams. This confronts us with a remarkable situation: Theorems of mathematics make it possible to support the notation for this same mathematics. We propose to analyse in detail this revenge of the hand which no longer content to drone out XI, X2, then $\mathrm{x} 3$ etc., as prescribed by linear successivity, but can play on all the routes permitted by the (interlacing) tracery. The notation contaminates to some extent the calculations, in order to create a new context like literary metaphor. ${ }^{7}$

Châtelet's invocation of the gesture appears to waver between poetic and pragmatic, yet this is hard to separate from our generally received notion of gestures as expressive additives to oration. Yet the gesture, which is something of a conceptual egg for metaphor (put metaphorically!), has an important function for Châtelet as a local articulation of abstract space. Again, this can appear too much a flight of fancy, or it can simply designate a 'working space' between the discrete and the continuous, between the quantitatively measured and the qualitatively constructed. This is not to divorce these actions, but merely emphasize that Châtelet is drawing the space where both physical objects and thought experiments take place.

While pulling from Schelling's notion of abstract space as a nest of forces and polarities, Châtelet emphasizes that metaphors function as 'allusive devices' particularly in scientific and mathematical thought experiments during the early I 9 th century. In particular, Châtelet explores how electrodynamics required the muscle of metaphorical creatures in order to advance concepts and configurations of forces which were not adequately expressible in then-contemporary ways. For instance, the treatment of electrodynamics in Châtelet's narrative moves from being presented as a geometrical peculiarity, to an anti-mechanistic fluid, to finally an updated celestial 'mechanics' made of particles and forces. Across these transitions, the metaphor allows a nascent theory to inhabit other established worlds (electricity as a fluid, electricity as a force) in such a manner that it is advanced, but never absorbed by, its host.

Thus, for Châtelet, neither a straightforwardly progressive nor a revolutionary model is satisfactory for describing the movements of science. To say, for instance, that the treatment of electric current as akin to the behaviour of fluid dynamics was simply a mistake would itself be an error in judgement since that metaphorical treatment of electricity as fluid fed into the attempt to contain it, i.e., in the construction of the first chemical batteries. Châtelet builds off Schelling's spatial

7 Gilles Châtelet, 'Interlacing the singularity, the diagram, and the metaphor', ed. Charles Alunni, in Virtual Mathematics: The Logic of Difference, ed. Simon Duffy (Bolton: Clinamen Press, 2006), 36. 
observation that while magnetism should be understood in terms of length, electricity should be understood in terms of width. Not only does this lead to eventually articulating the electrical field, it also means that width could no longer be understood as simply an external measurement upon a given chunk of physical material. While length seems to be the active adventure of a point, a trajectory which we can project ourselves into the horizon (aware of the scarring mentioned above) width takes on an altogether different understanding with the electric field since these fields return to their origin point, to zero. However, the ' 0 ' of the electrical field is not a motionless starting point as it is with 'you are here' and the horizon, it is a point between two different trajectories which are not straight or towards anything other than itself.

As Châtelet points out, electric thinking opens up the notion of a non-neutral zero since a negative charge is active, albeit in a different way. The association of the electric with a fluid makes sense given the fact that the understanding of the mechanical at the time could not account for fields of energy, for two different kinds of forces emanating from one point (the closest analogy being that of the polarization of a magnet). As he writes, "Electrical positivity is not that of accumulation, but that of current that loops the around opened by separation [...] The metaphor of the positive and negative 'fluids' had attempted to counter the 'self-evidence' of the solid and manipulable units of mechanics." Chemical difference (the ions of different elements) when bridged by a transmitting fluid (salt water or many other mediums) produces a looping flow of energy. Thus a battery becomes a capture of a loop of current that, when given a release or an outlet, becomes a power source.

As Schelling was aware, as Châtelet notes, there was a temptation to explain the polarities of a battery with the polarities of the magnet, i.e., equating the positive with the north and the negative with the south. ${ }^{9}$ But Faraday's and other investigations into the physical body of the magnetic and the chemical body of the battery demonstrated that electromagnetism provided thought with a motion that explained the emergence of bodies themselves. Instead of bodies in motion, electrodynamics and its relation to magnetism starts to give us an idea of space that can issue bodies out of forces. ${ }^{\text {IO }}$

These lines of force "are neither 'real' wires nor illustrations of knowledge already deposited in an encyclopedia; they lead the exploration of a field which is neither exactly in Nature nor exactly in Understanding." ${ }^{\mathrm{II}}$ Furthermore, and as Maxwell realized, it is a space of force that allows one to see the interaction of the lines as interlacing and

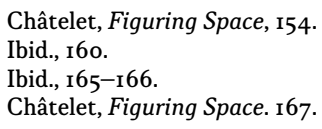


as knots in order to understand bodies as both the result and the perturber of a cosmos of forces. With the metaphor of the screw, of a flick of the wrist (as gesture), one can understand how an axial motion can seem to affect or penetrate space itself, i.e., rational movement is translated into a direction through the metaphor of the gear wheel or the corkscrew. Thus, Châtelet argues that metaphors of Maxwell function as a Trojan horse in order to breach the fortress of the mechanical imaginary. ${ }^{12}$

One could easily forget this entire chemical path in viewing an entity such as a black hole as merely a cosmic corkscrew or whirlpool. Yet without the knowledge gained from the electric, to the chemical, to the electro dynamic, a black hole would certainly not be black, or time-slowing, or ravenous. Furthermore, it explains, for better or for worse, why much of contemporary physics can gain so much explanatory (at least mathematically) traction in following Châtelet's secularization of the invisible through the making of knots in the vibratory fabric of space. Or, diagrammatically, it is not such a long journey from lines of force to quantum strings.

\section{CONCLUSION}

It may be that the above use of metaphor can be deemed trivial. I hope, however, that it at least demonstrates a valiant effort to demonstrate an alliance between two supposedly divided halves of the world: the quantitative and the qualitative. While Châtelet is often discussed as a follower of Deleuze, and is dismissed too quickly as much by Alain Badiou as others, Châtelet's emphasis on metaphor as well as his attitude towards mathematics carves out an important space between Deleuze and Badiou, and suggests that the mathematical and the vital are not so violently at odds with one another.

In his I 968 lectures on Kant and the Synthesis of Time, Deleuze and Châtelet engage in a brief exchange regarding the role of mathematical construction in relation to time. Deleuze invites Châtelet to say something about the mathematical treatment of time in antiquity vis$\dot{a}$-vis Kant's modern concept of time as synthesis. Importantly, where Deleuze and Châtelet disagree is in regard to the link between measure and parameter. Châtelet insists that the two are different:

The parameter is not a result. A number, for the Greeks, is simply a measure, here the measure of time is possible because ... in mathematics parameter has no definition, it's simply a notion. Time become parameter is no longer a result, it becomes an initial given. A parameter is what is given, what varies. 


\section{Deleuze responds:}

I think that it amounts to exactly the same thing: to say that time ceases to be a number or that time ceases to measure something and thus is subordinated to what it measures, and that time becomes a parameter, time is related to a problem of constitution. When I said that time un-curves itself, becomes a straight line ... There is something equivalent in this modern conception of time where it is at the same time that an empty form of parametric time appears and a complementarity with something which makes a function, whether it is the caesura in the tragedy, or else the cut in mathematical instrumentation. I am just a bit bothered by the key role that Gilles Châtelet gives to Plotinus. ${ }^{13}$

In essence, Châtelet argues that the difference between the Greek's notion of time as eternity, on the one hand, and a measure of cyclical change on the other, is not radically different from Kant's treatment of space as a necessary ( $a$ priori) condition for the possibility of experience connected to inner sense. This bothers Deleuze because he thinks one of Kant's great accomplishments is the freeing of time from eternity and becoming a tool of the subject, a constructive aspect of experiential synthesis. Yet it seems that Châtelet wants to be more careful when it comes to construction - a line of measure is not an abstract line which, on the one hand, one could argue is somewhat supported by Kant's use of magnitudes as the basis for the inner sense's intensity and thus arithmetic. Both measurable and metaphorical captures of intensity productively soften the stitches binding experience to subjectivity.

This in the end may be the difference which Châtelet's metaphors reveal in all their romantic recklessness - that while Châtelet can support Schelling's dictum that being (as nature) precedes thinking, Deleuze's final turn to Fichte betrays the opposite tendency. 

